\title{
The Way to Solve the Hong Kong Problem—— from the Perspective of Educational Reform
}

\author{
Yuqing Ding* \\ Yunnan University, Kunming, Yunnan, 650504, China
}

\section{ARTICLE INFO}

Article history

Received: 14 January 2021

Revised: 21 January 2021

Accepted: 9 April 2021

Published Online: 16 April 2021

Keywords:

National identity

National education

Hong Kong

\begin{abstract}
The civic education in Hong Kong schools is not only valued and successful, but also controversial. In the process of implementing "one country, two systems" in Hong Kong, especially in recent years, some new situations and new problems have emerged, a series of fierce social movements have continuously erupted, and some social and political disputes have continuously emerged. some Hong Kong students in citizens' political participation has gradually turned out to be the object of the "street politics" endures, even turned into 'thugs', Hong Kong, triggered a strong concern of the whole society. In order to strive for certain demands, these students have shown themselves to the public with outrageous, fanatical and even extreme actions, which run counter to the goal and purpose of Hong Kong's civic education and have also been suspected of crimes. Faced with the uncontrollable political fanaticism of some students, summarize the experience and lessons of civic education in Hong Kong schools, formulate corresponding programs and measures in a targeted manner, and further improve them.
\end{abstract}

\section{Introduction}

Hong Kong is a special administrative region of China. The higher education in Hong Kong is an integral part of China's higher education system. Although the overall level of teaching and research and the degree of internationalization of Hong Kong's higher education are relatively high, due to historical and practical reasons, in a period of time, the higher education in Hong Kong has not paid enough attention to the needs of economic and social development, and the advantages of serving the national development are not obvious, which makes the higher education in Hong Kong fail to better integrate into the overall situation of national development. The reform of higher education in Hong Kong is a steady and orderly process, which requires the cooperation and participation of the government, universities and teachers and students. The reform of Hong Kong's higher education cannot be achieved overnight. It requires all sectors of society to seize the opportunity and make joint efforts to better integrate Hong Kong's higher education into the overall situation of national development, so that it can achieve its own long-term sustainable development while contributing to national construction.

\section{The Hong Kong Problem}

Since June, 2020, serious illegal actions of black-

*Corresponding Author:

Yuqing Ding,

Yunnan University, Kunming, Yunnan, 650504, China;

E-mail:2126828166@qq.com. 
clad thugs smashing, smashing, looting and burning have broken out almost every weekend in Hong Kong, and the number of people arrested by the police has exceeded 7000 as of January 16. More worryingly, the proportion of college and middle school students among these detained suspects is as high as $40 \%$. Of the more than 470 secondary schools in Hong Kong, it is reported that at least one student has been arrested.

Young people have become the main participating group, and "the unhealthy trend of containment of a small number of trouble-making college students in Hong Kong has spread to secondary school campuses", making the trend of "street politics" more and more young. These seemingly high-sounding civil rights protests are mostly carried out by means of illegal occupation, illegal assembly and even violence, which are despised by all sectors of society and the general public ${ }^{[1]}$. Because primary and secondary school students lack the ability to distinguish right from wrong and think independently, their thoughts and behaviors are easily affected. This phenomenon is undoubtedly worrying and completely runs counter to the purpose and purpose of the current implementation of civic education in schools.

After 1997, when Hong Kong was reunited with the motherland, an important task facing the country was to enhance Hong Kong people's sense of national identity. Hong Kong returned to China in 1997, and this historical moment is also very exciting. Hong Kong has been away from the motherland for more than 100 years, and now it has finally returned to the embrace of the motherland. Hong Kong has been away from the motherland for more than 100 years, and the mainland is relatively unfamiliar with Hong Kong in all aspects, especially the new generation of young people.

\section{The Way to Solve the Hong Kong Problem}

Due to the special history of Hong Kong, before the reunification, they all received civic education that emphasized individual rights and obligations, and there was no sense of identity and belonging to the country, This is particularly true for young people in the new age. Therefore, promoting national education for students and enhancing national identity are in line with Hong Kong and the world, which is also the aspiration of the people.

National consciousness education is a part of civic and political education. In terms of the requirements of the situation since Hong Kong's return to the motherland, national education should be the core content of civic and political education, and then it should also become the core content of civic education in Hong Kong schools. Public opinion also has misunderstandings about civic political education, which leads to great controversy. Through social disturbances such as "Occupy Central" and "Mong Kok riots" in recent years, many Hong Kong people have shifted their responsibility to "general subjects with political education overtones". If we say that the "non-politicized" educational orientation in the colonial education period is the original sin of safeguarding colonial rule and leading to Hong Kong people's political apathy at that time. Is it certain that today's social chaos must be caused by "overcorrection" in civic and political education ${ }^{[1]}$. This is precisely not the case. On the contrary, civic and political education is inadequate and unadaptable, otherwise there would not be so many illegal, irrational and other chaotic phenomena that violate the purpose of civic education. Therefore, civic and political education can only be strengthened, not weakened. The "one country, two systems" practice has been universally recognized. The fundamental objective of the central government's policies and policies towards Hong Kong is to preserve national sovereignty, security and development interests and to maintain Hong Kong's long-term prosperity and stability. After the return of Hong Kong, many people did not understand correctly and did not realize that they were Chinese citizens. The generation of young people who grew up after the return of Hong Kong does not have a sufficient knowledge of Chinese history ${ }^{[2]}$.

Therefore, fundamentally speaking, to do a good job in political education in civic education in schools is to fully and accurately understand and implement the general principle of "one country, two systems" principle and policy, and to profoundly grasp "gradual and orderly progress in accordance with the law." finally achieve universal suffrage, the general tone of democratic development ${ }^{[3]}$. Adherence to the principles of the state must be combined with respect for the differences between the two systems, the maintenance of the central government authority, and the maintenance of a high degree of autonomy in the special administrative areas. Giving full play to the strong backing role of the mainland of the motherland and improving Hong Kong's own competitiveness. The central implementation of "the fundamental policy of one country, two systems will not change; The determination to support the administration of the Hong Kong government in accordance with the law and to discharge its responsibilities will not change; The policy of supporting economic development, improving people's livelihoods, promoting democracy and promoting harmony in the Hong Kong 
administrative district will not change. The fate of Hong Kong and mainland China has always been closely linked.

Therefore, education reform Brooks no delay. First of all, we must attach importance to history education. First, history directly helps students to think and provide resources to make them good citizens; second, history allows students to sort out causality by showing them the context of events, so as to improve their ability of judgment; Dilan, through the study of the knowledge of the country's history, edify the students' patriotism. History education in Hong Kong has not been taken seriously in school education. The new generation of young people in Hong Kong have not fully understood the history and culture of the motherland for more than 5,000 years, so their patriotic enthusiasm has not improved. Therefore, history education should be paid attention to; secondly, the content of national education should be comprehensive and balanced. Only when we really understand everything about the motherland, can we really love the country from the bottom of our heart. The scope of loving the motherland is more extensive, and the channels are also more diverse $^{[4]}$. Organize Hong Kong students to visit the mainland to personally experience China's beautiful mountains, rivers and local conditions; through the broadcast of documentaries and other forms to let students understand the real Chinese culture. Through visits to museums and memorials to introduce students to the advanced deeds of the country's outstanding historical figures, and so on, national education should not only emphasize patriotic education, but also highlight the education of loving the motherland. Due to complex historical reasons, the social system of Hong Kong is different from that of the mainland of the motherland, but this does not change the identity of their descendants of the Chinese people or the fact that they are Chines $\mathrm{e}^{[5]}$. Although their awareness of national education is weak, through the role of education, through their own feelings and increasingly close exchanges between the two places, national education can certainly achieve the desired goal.

The people of Hong Kong will certainly be able to return to the motherland in a real sense. Moreover, as far as the government is concerned, it is necessary to improve the top-level design and governance orientation. Education plays a leading and fundamental role in social development. Civil education in Hong Kong schools should be adapted and reformed in accordance with the requirements of Hong Kong's economic, social and democratic developments under the new circumstances, and the first thing to bear the brunt is to delete and rewrite the outdated curriculum guidelines that do not meet the requirements of the new situation ${ }^{[6]}$. It is necessary to grasp civic education on the one hand and "decolonization" on the other.

National education is mainly carried out in countries with national characteristics education, and this sense of reality is also very strong. To carry out education on national conditions, we should draw lessons from the "anti-national religion storm" and avoid such practices as "imposing on students", "reporting good news but not reporting bad news", "empty preaching", "one-way indoctrination" and so on. Although the subject of national education has been shelved due to the "anti-national religion disturbance", national education is still permeated and hidden $^{[7]}$.

Young people in Hong Kong represent not only the future of Hong Kong, but also the future of the Chinese nation. They have witnessed and carried forward the principle of "one country, two systems". It is their responsibility to maintain coordinated development and common prosperity in both countries. Hong Kong's prosperity and stability are inseparable from its political confidence and determination. This is especially true for young people. Therefore, ideological and political education plays an indispensable leading role. In November 2019, the CPC Central Committee and the State Council issued the Implementation Outline of Patriotism Education in the New Era, which pointed out that "youth should be taken as the top priority of patriotism education, the patriotism spirit should be run through the whole process of school education, and patriotism education should be promoted into the classroom, teaching materials and mind ${ }^{\text {[[] }}$. Therefore, deepening the reform of Hong Kong's general education system in an all-round way, continuously enriching and improving the content of Hong Kong's youth patriotism education, and realizing the connection between Hong Kong's general education and mainland's moral education are the urgent tasks for Hong Kong's youth to strengthen their national identity, especially their national identity, and cultivate a new era of Hong Kong's youth with the national concept and Hong Kong's feelings.

We will internalize patriotism in our hearts and externalize it in our actions.Hong Kong's prosperity and stable development depend on Hong Kong youth's ideological and political recognition and integration into the Chinese nation $^{[8]}$.

\section{References}

[1] Benson P L, Mannes M, Pittman K, et al. Youth Development, Developmental Assets, and Public Policy 
[M]. John Wiley \& Sons, Ltd, 2004.

[2] Chen Jiangling. New West (theoretical Edition), 2016 (22): $42-43$

[3] Shen BENQIU. Concept challenge and system shortage: difficulties in the construction of national identity of Hong Kong people —_ Taking the problem of national education in Hong Kong as an example [J]. Scientific socialism, 2016 (05): 137-142.

[4] He Zhiping. Hong Kong Youth: Problems and solutions [J]. Hong Kong and Macao Studies, 2015 (01):
$73-82+96$.

[5] Lu Dakun, Jin Mingzhi. Academic theory, 2014 (15): 157-158.

[6] Wang Xuefeng, cen Hui. Education review, 2008 (01): 108-111.

[7] Chang Le. The adjustment of Hong Kong's education policy in the "post occupation" period [J]. Journal of Guangdong Institute of socialism, 2015 (04): 41-46.

[8] He Yingfeng. Sohu.com, August 26, 2019. 